\title{
Optimization of Variables Influencing the Thermal Conductivity and Fracture Strength of Reinforced PMMA by Using the Taguchi Method
}

\author{
ESRA KUL ${ }^{1 *}$, FARUK YEŞILILAL ${ }^{2}$, EMRE MANDEV $^{3}$, CAFER ÇELİK $^{4}$ \\ ${ }^{1}$ Department of Prosthodontics, Faculty of Dentistry at Atatürk University, Erzurum, Turkey \\ ${ }^{2}$ Department of Mechanical Engineering, Faculty of Engineering at Atatürk University, Erzurum, Turkey \\ ${ }^{3}$ Department of Mechanical Engineering, Faculty of Engineering and Architecture at Erzurum Technical University, \\ Turkey \\ ${ }^{4}$ Department of Industrial Engineering, Faculty of Engineering at Atatürk University, Erzurum, Turkey
}

\begin{abstract}
How the particle size and volumetric ratio of silicon carbide (SiC) powder additions will strengthen polymethyl methacrylate (PMMA) is unclear. The purpose of this in vitro study was to optimize the reinforcement parameters of PMMA with SiC powder by using the Taguchi experimental design method. Particle size, volumetric rate, silane coupling rate, and mixing type were determined as parameters that would affect the reinforcement of PMMA with SiC powder. Using the Taguchi L9 orthogonal array, test specimens with different parameter combinations were fabricated and tested. The fracture load (in newtons) of each specimen group was recorded with the 3-point bend test. The thermal conductivity values of $60 \times 50-\mathrm{mm}$ and 3-mm-thick rectangular specimens were measured by using the Linseis THB100 thermal conductivity unit. The thermal diffusivity values were then calculated. Thermal analysis indicated improvement in the thermal conductivity of PMMA after reinforcement with SiC. The maximum thermal diffusivity was obtained with $15 \%$ SiC powder by volume. Thermal conductivity and flexural strength increased with an increase in particle size. The maximum flexural strength value was obtained with 5\% SiC powder by volume. Increasing the particle size of the filler SiC powder resulted in increased thermal conductivity and flexural strength. Increasing the SiC filler powder by volume increased the thermal conductivity of PMMA but reduced its flexural strength. This study helped determine the optimum conditions for the use of SiC powder. Knowledge of the importance of these variables will help in more effective modification of denture base resin with SiC powder to improve heat transfer without adversely affecting strength.
\end{abstract}

Keywords: denture base material, Taguchi method, SiC powder, thermal conductivity

\section{Introduction}

Polymethyl methacrylate (PMMA) is the most widely used complete denture base material [1]. However, as temperature affects taste perception, complete denture users have difficulty tasting food because of the poor thermal conductivity of PMMA [2-4], which may affect prosthesis satisfaction [5,6]. A denture base with high thermal conductivity will improve both tissue health [7] and taste and prevent the patient from rejecting the prosthesis as a foreign body [7-9]. Different materials with high thermal conductivity, such as thermally conductive ceramics, may be more suitable than metal powders for increasing the thermal conductivity of PMMA [10,11]. because most of these ceramics have a thermal conductivity similar to that of metals $[10,12]$. Also, since ceramic fillers have a low density, they do not significantly increase the weight of the prosthesis [10].

Since the bonds in silicon carbide ( $\mathrm{SiC}$ ) are highly covalent, it is more durable than oxide ceramics, has high thermal conductivity and low density, and is very hard and thermally stable. With good biocompatibility and excellent cytocompatibility, it is suitable for use in medical implants and prostheses [13-17].

*email: esra.kul@atauni.edu.tr 
A material with high thermal conductivity is more suitable than a reduction in thickness for improving heat transfer, because prosthesis thickness cannot always be reduced [18]. The thickness of the denture base is effective in heat diffusion [19]. Thermal diffusion (thermal dispersion) is considered the most important factor in sensing intraoral temperature changes because the thermal diffusivity, defined as the ratio of transmitted heat to stored heat (volumetric), measures the heat transfer rate of a material from the hot end to the cold end [20,21]. In previous studies [7,10,11,22,23] designed to increase the thermal conductivity of PMMA, electron microscopy images showed that SiC powders added to PMMA dispersed homogeneously, increasing thermal conductivity without negatively affecting bend strength; however, new approaches are needed.

The Taguchi Method [24-26] was initially developed by Taguchi, who showed that experimental designs could be used to adjust variability around a target minimum [27] This process has been used to obtain more robust products by changing components after bringing the mean performance value to the target value, determined by its production and by controllable and uncontrollable processes [28-30]. With the Taguchi test method, the cost of experimenting decreases, the material used decreases, and the tests can be completed in a shorter time [31,32]. During this process, the Taguchi experimental design method uses tools such as the orthogonal array (OA), performance statistics, and loss function [33].

The purpose of this in vitro study was to use the Taguchi experimental design method to add SiC powder of different particle size, volumetric rate, silane coupling rate, and mixing type to determine the parameters affecting PMMA and to investigate the thermal diffusivity and flexural strength of the modified PMMA. The null hypothesis was that all parameters examined would not affect the thermal conductivity or flexural strength.

\section{Materials and methods}

Rectangular stainless steel molds $(3 \times 10 \times 65 \mathrm{~mm})$ were prepared for the 3 -point bend test in accordance with the ISO 1567 standard $[22,34,35]$ and $60 \times 50 \times 3$ stainless steel molds were prepared for the thermal conductivity test in accordance with the ASTM E1530-06 [36] standard. The molds were placed in muffles with Type II gypsum (Moldano; Kulzer GmbH) under 14-MPa pressure for 30 min in a hydraulic press (Carlo de Giorgi). After the gypsum had hardened, the molds were removed with a spatula.

Conventional heat-polymerized denture base material (Meliodent; Kulzer $\mathrm{GmbH}$ ) and filler powders were weighed on a balance with 0.0001-g precision (FGH 200; Dikomsan) for each experiment (Table 2). Silane was added to improve the bonding of the $\mathrm{SiC}$ powders to the polymer matrix. In the silanization process, $70 \%$ ethanol solution was prepared by using distilled water and ethanol with $p \mathrm{H} 4.5$ for each experimental group [28].

3-methacryloxypropyltrimethoxysilane (MTS) was added in the different proportions required for the experiment type (Table 2), hydrolyzed, and silanized [37]. After the filler powders had dried in an oven at $62^{\circ} \mathrm{C}$ for $1 \mathrm{~h}$, filler powders were mixed with the PMMA powder in the different proportions. Mechanical alloying of the filler powder and PMMA was done with zirconia balls and a mill (Planetary Ball Mill PM 400; Retsch). The filler powder and PMMA were stirred with a mixer (Finevortex; FINE) by using stainless steel balls. The mixing was manual with a stick; no devices were used. Methylmethacrylate liquid was then added. When the acrylic resin reached a doughy consistency, it was placed in the mold cavity, and the flasks were sealed and pressurized at $14 \mathrm{MPa}$ for 5 min under a hydraulic press. Compressed mufflers were boiled for $2 \mathrm{~h}$. The specimens were polished using 320-, 600-, and 1200-grit abrasive paper. Flexural strength was measured with the 3-point bend test on a universal testing machine (model 3344; Instron Ltd) [10].

Experiments following the Taguchi experimental design method [27] were carried out to determine the effect of parameters on the thermal diffusivity and flexural strength of PMMA (Table 1). Thermal diffusivity and maximum flexural strength were regarded as performance characteristics, and a Taguchi L9 $\left(3^{4}\right)$ orthogonal array was used as the experimental plan for the 4 parameters: particle size, volumetric 
rate, silane coupling rate, and mixing type of $\mathrm{SiC}$ powder and PMMA. Eighteen experiments were carried out by using the $\mathrm{L} 9\left(3^{4}\right)$ experimental layout with the Taguchi method instead of performing $3^{4}=81$ experiments with a complete factorial design.

The combination of parameters, total number of experiments, and examined results are specified in Table 2. The L9 orthogonal array (OA) was chosen as it was the most suitable for the conditions being investigated.

Table 1. Experimental parameters and their levels

\begin{tabular}{|c|c|c|c|}
\hline \multirow[b]{2}{*}{ Parameters } & \multicolumn{3}{|c|}{ Levels } \\
\hline & 1 & 2 & 3 \\
\hline Particle size, A ( $\mu \mathrm{m})$ & 0.2 & 37 & 125 \\
\hline Volumetric rate, B (\%) & 5 & 10 & 15 \\
\hline Silane coupling rate, $\mathrm{C}(\%)$ & 0.5 & 1 & 1.5 \\
\hline Mixing type, $\mathrm{D}$ & Manual & Stir & Mechanical alloying \\
\hline
\end{tabular}

Table 2. Experimental layout and corresponding results

\begin{tabular}{|c|c|c|c|c|c|c|c|c|}
\hline \multirow[t]{2}{*}{ Exp. No } & \multicolumn{4}{|c|}{ Parameters } & \multicolumn{4}{|c|}{ Results } \\
\hline & $\mathrm{A}(\mu \mathrm{m})$ & $\begin{array}{l}\mathrm{B} \\
\%\end{array}$ & $\mathrm{C}(\%)$ & D & TD-1 & TD-2 & MS-1 & MS-2 \\
\hline 1 & 0.2 & 5 & 0.5 & Manual & 0.1255 & 0.1222 & 69.33 & 70.50 \\
\hline 2 & 0.2 & 10 & 1 & Stir & 0.1223 & 0.1228 & 64.75 & 66.67 \\
\hline 3 & 0.2 & 15 & 1.5 & Mec.alloying & 0.1373 & 0.1348 & 30.67 & 32.17 \\
\hline 4 & 37 & 5 & 1 & Mec.alloying & 0.1293 & 0.1249 & 68.33 & 72.92 \\
\hline 5 & 37 & 10 & 1.5 & Manual & 0.1234 & 0.1239 & 69.83 & 74.25 \\
\hline 6 & 37 & 15 & 0.5 & Stir & 0.1422 & 0.1387 & 75.58 & 72.75 \\
\hline 7 & 125 & 5 & 1.5 & Stir & 0.1309 & 0.1276 & 92.17 & 94.58 \\
\hline 8 & 125 & 10 & 0.5 & Mec.alloying & 0.1291 & 0.1270 & 70.17 & 70.67 \\
\hline 9 & 125 & 15 & 1 & Manual & 0.1452 & 0.1417 & 85.25 & 87.33 \\
\hline
\end{tabular}

Thermal diffusivity and flexural strength were considered as performance characteristics. The performance statistic was chosen as the optimization criterion. "The larger the better" situation was chosen both for the thermal diffusivity and friction factor. The performance statistics were assessed from the following equation [24]:

$$
Z_{B}=-10 \log \left(\frac{1}{n} \sum_{i=1}^{n} \frac{1}{Y_{i}^{2}}\right)
$$

where $\mathrm{Z}_{\mathrm{B}}$ denotes performance statistics, $\mathrm{Y}_{\mathrm{i}}$ the performance value of the $i$ th experiment, and $\mathrm{n}$ the number of repetitions carried out for an experimental combination. In the Taguchi method, the experiment corresponding to the optimum conditions may not have been carried out for the entire duration of the experiments. In the current state, the performance value corresponding to optimum operating conditions was estimated by using the balanced characteristic of OA. For this reason, the additive model given as follows was used to predict the effect of the parameters [38]:

$$
Y_{i}=\mu+X_{i}+e_{i}
$$


where $\mu$ denotes the comprehensive mean of performance value, $X_{i}$ the effect of the parameter level combination applied in the $i$ th experiment, and $e_{i}$ the random error in the $i$ th experiment. Calculations were made by using experimental data to determine whether the results of the verification experiments were valid. Additionally, the confidence interval was calculated as follows by [38]:

$$
Y_{i} \mp \sqrt{F_{\alpha ; 1, D F_{M S e}} M S e\left(\frac{1+m}{N}+\frac{1}{n_{i}}\right)},
$$

where $\mathrm{F}$ is the value of the $\mathrm{F}$ table, $\alpha$ indicates the error level, $\mathrm{DF}_{\mathrm{MSe}}$ is the degree of freedom of the mean square error, $m$ denotes the degree of freedom used in the prediction of $Y_{\mathrm{i}}, n_{i}$ is the number of repetitions in the confirmation experiment, and $\mathrm{N}$ is the number of total experiments.

The thermal conductivity coefficient was measured by using the Linseis THB100 thermal conductivity device, measuring with the temporary thermal bridge (THB) technique [39]. After calculating the thermal conductivity coefficient, the thermal diffusivity coefficient was calculated by using [10]

$$
\alpha=\frac{\text { conducted heat }}{\text { stored heat }}=\frac{k}{\rho C_{p}} \quad\left[\mathrm{~m}^{2} / \mathrm{s}\right],
$$

where $\mathrm{k}$ is the coefficient of heat conduction $[\mathrm{W} / \mathrm{mK}], \rho$ is density $\left[\mathrm{kg} / \mathrm{m}^{3}\right]$, and $\mathrm{C}_{\mathrm{p}}$ is specific heat. Thermal diffusivity is a measure of the thermal energy storage ability of materials. In addition, control of the homogeneous distribution in the internal structure of the composite material was carried out by scanning electron microscopy (SEM) (FEG 250; Quanta, FEI Company) analysis.

\section{Results and discussions}

The Taguchi experimental design method was used to designate the best variation (composition) for the reinforcement of PMMA using SiC powder. As seen in Figure 1, thermal diffusivity increased with increasing particle size. The maximum thermal diffusivity was obtained at the third level of the $\mathrm{SiC}$ powder volumetric rate (15\%). For the parameters of mixing type and silane coupling rate, the values of thermal diffusivity were close to each other.

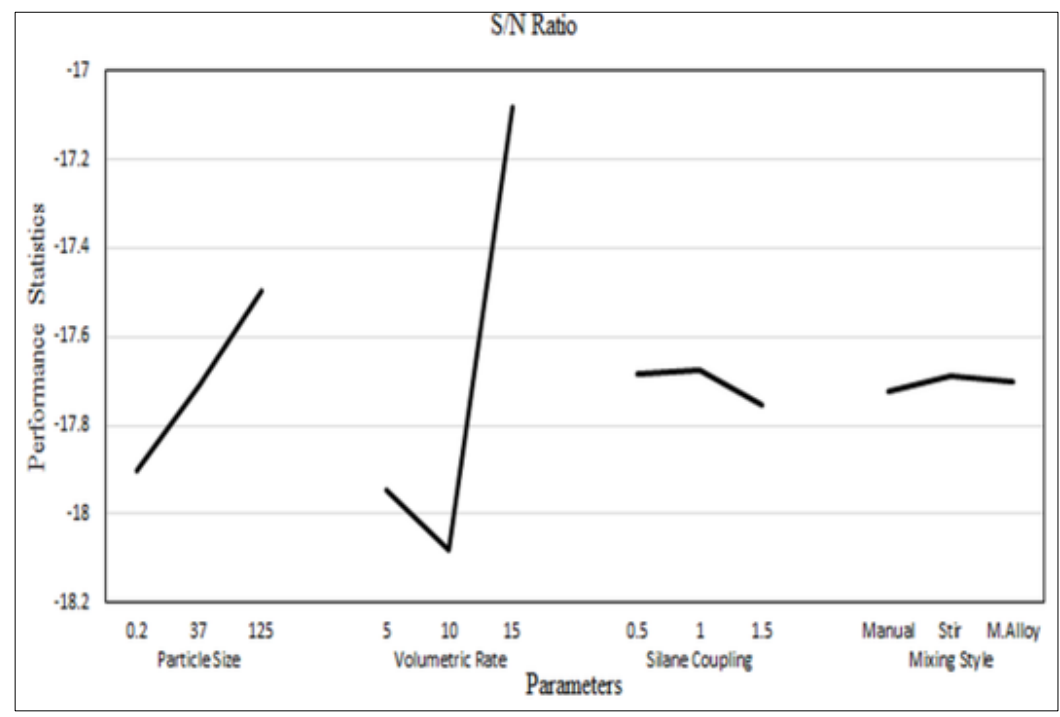

Figure 1. Effect of each parameter on thermal diffusivity. S/N, signal to noise 
As seen in Figure 2, the maximum flexural strength increased with increasing particle size. The maximum flexural strength value was obtained at the first level for the SiC powder volumetric rate. Also, the maximum flexural strength decreased with the increase of the $\mathrm{SiC}$ volumetric rate. Maximum flexural strength value was obtained at the second level for the parameter of silane coupling rate. Similarly, the second level of mixing style produced the maximum flexural strength.

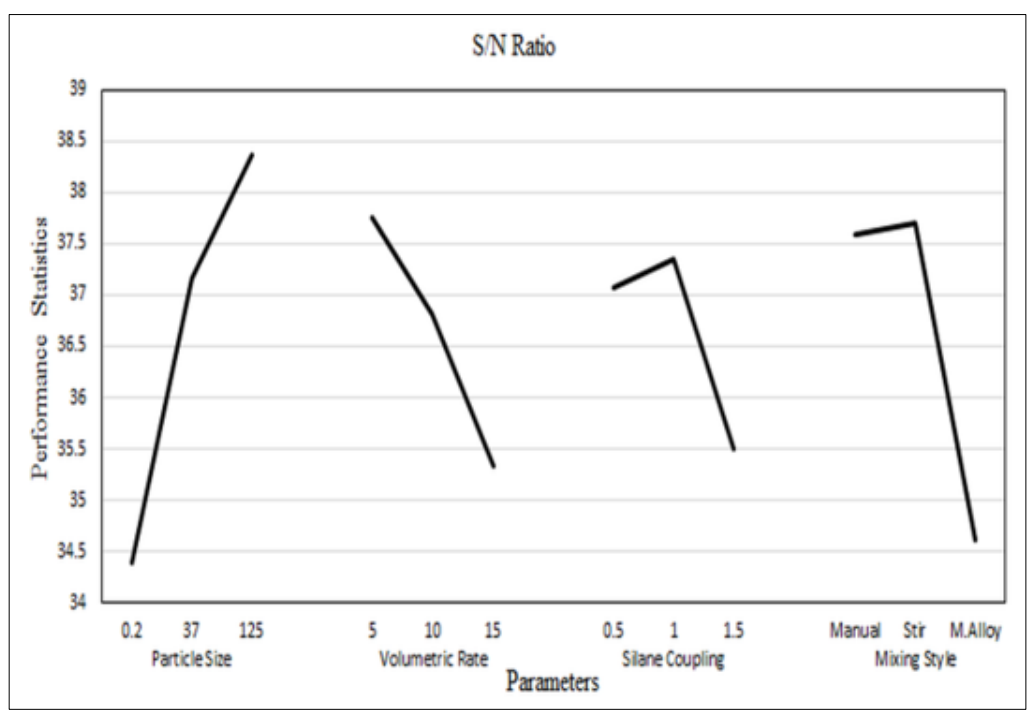

Figure 2. Effect of each parameter on flexural strength. $\mathrm{S} / \mathrm{N}$, signal to noise

The contribution ratio refers to the effects of each factor in the process. The parameter with the highest contribution value indicates the most effective parameter on performance characteristics. The $\mathrm{SiC}$ volumetric rate was the most effective parameter among the parameters on thermal diffusivity, with a contribution ratio of $87 \%$ (Figure 3), indicating that heat transfer was enhanced as volumetric rate increased.

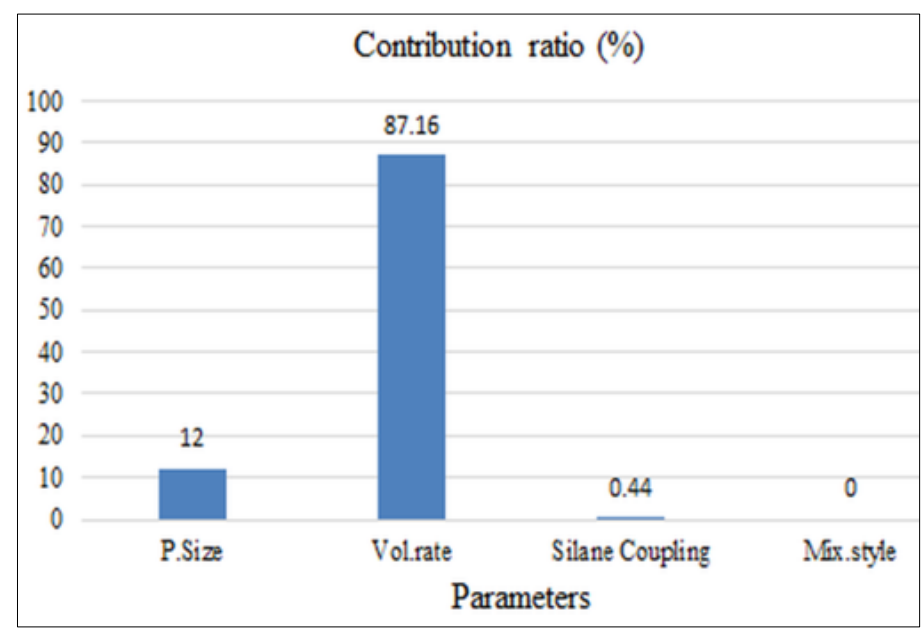

Figure 3. Contribution ratio of each parameter on thermal diffusivity. Mix, mixing; P, particle; Vol, volume

SiC powder size was the most effective parameter among the parameters on maximum stress with a contribution ratio of $32.4 \%$ (Figure 4). Mixing style had a contribution ratio of $21.3 \%$ on maximum stress. 


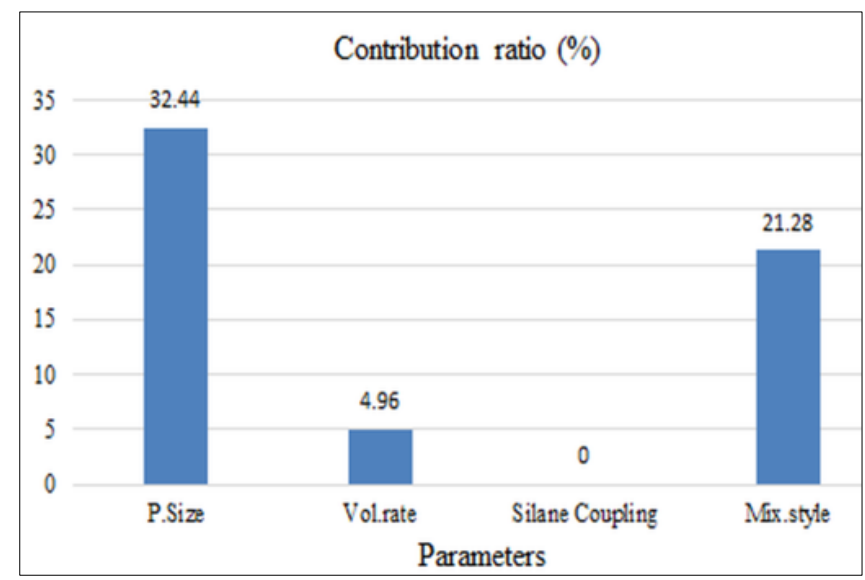

Figure 4. Contribution ratio of each parameter on flexural strength. Mix, mixing; P, particle; Vol, volume

The optimum values of thermal diffusivity and maximum stress were predicted by using Equation 2 (Table 3). From Equation 3, the predictions for both thermal diffusivity and maximum stress were obtained at a confidence interval of 95\% (Table 3). Two validation experiments, performed under optimum conditions (Table 3), were within the confidence interval. Therefore, the interactive effects of the parameters were not significant.

Table 3. Optimum conditions and performance values

\begin{tabular}{|c|c|c|c|c|c|c|c|c|c|c|c|}
\hline & \multicolumn{4}{|c|}{ Parameters } & \multicolumn{6}{|c|}{ Performance Values } \\
\hline & & $\mathrm{A}$ & $\mathrm{B}$ & $\mathrm{C}$ & $\mathrm{D}$ & \multicolumn{3}{|c|}{ Thermal Diffusivity } & \multicolumn{3}{|c|}{ Maximum Stress } \\
\hline & & $\begin{array}{c}\text { Particle } \\
\text { size }\end{array}$ & $\begin{array}{l}\text { Volumetric } \\
\text { rate }\end{array}$ & $\begin{array}{c}\text { Silane } \\
\text { coupling }\end{array}$ & Mixing style & Prediction & \begin{tabular}{|c} 
Confidence \\
Interval \\
\end{tabular} & Real & Prediction & $\begin{array}{c}\text { Confidence } \\
\text { Interval } \\
\end{array}$ & Real \\
\hline & $\begin{array}{l}\text { Optimum } \\
\text { level }\end{array}$ & $\mathrm{A}_{3}$ & $\mathrm{~B}_{3}$ & $\mathrm{C}_{2}$ & $\mathrm{D}_{2}$ & & & & & & \\
\hline \multirow[t]{3}{*}{$\begin{array}{c}\text { Thermal } \\
\text { Diffusivity }\end{array}$} & $\begin{array}{l}\text { Optimum } \\
\text { value }\end{array}$ & 125 & 15 & 1 & Stir & \multirow[t]{2}{*}{0.1431} & \multirow[t]{2}{*}{$\begin{array}{c}0.1382--- \\
0.1480\end{array}$} & \multirow[t]{2}{*}{0.1460} & \multirow[t]{2}{*}{87.88} & \multirow[t]{2}{*}{$\begin{array}{l}81.50-- \\
94.26\end{array}$} & \multirow[t]{2}{*}{89.96} \\
\hline & $\begin{array}{c}\text { Contribution } \\
\text { ratio }\end{array}$ & 12.00 & 87.16 & 0.44 & - & & & & & & \\
\hline & $\begin{array}{l}\text { Optimum } \\
\text { Level }\end{array}$ & $\mathrm{A}_{3}$ & $B_{1}$ & $\mathrm{C}_{2}$ & $\mathrm{D}_{2}$ & & & & & & \\
\hline \multirow[t]{2}{*}{$\begin{array}{l}\text { Maximum } \\
\text { Stress }\end{array}$} & $\begin{array}{l}\text { Optimum } \\
\text { value }\end{array}$ & 125 & 5 & 1 & Stir & \multirow[t]{2}{*}{0.1298} & \multirow[t]{2}{*}{$\begin{array}{c}0.1249 \\
0.1347\end{array}$} & \multirow[t]{2}{*}{0.1255} & \multirow[t]{2}{*}{101.97} & \multirow[t]{2}{*}{$\begin{array}{l}95.59 \ldots- \\
108.35\end{array}$} & \multirow[t]{2}{*}{99.21} \\
\hline & $\begin{array}{c}\text { Contribution } \\
\text { ratio }\end{array}$ & 32.44 & 4.96 & -- & 21.28 & & & & & & \\
\hline
\end{tabular}

The thermal and mechanical properties of PMMA can be improved through material reinforcement and composition changes. According to the results of the present study, experimental parameters were found to affect thermal conductivity and flexural strength and therefore the null hypothesis was rejected. The addition of $\mathrm{SiC}$ nanoparticles to acrylic resin denture base material has been reported to improve thermal conductivity and surface hardness, with no significant decrease in transverse strength [14]. In the present study, the parameters of reinforcement of PMMA with SiC powder were assessed by using the Taguchi experimental design method. With this method, the optimal combination of chosen parameters was obtained [29,31]. Knowledge of the importance of these variables will help in the more effective use of reinforcement with $\mathrm{SiC}$ powder in dentistry. The Taguchi method provides a systematic approach for optimizing quality, performance, and cost [30]. Compared with experimental methods, the advantage of the Taguchi method is that it reduces the experimental cost and minimizes variability around the target when performance is optimized [32]. Furthermore, optimal working conditions can be reproduced from the study in actual applications [33]. The optimum conditions should be determined by analysis of the obtained results from the designed experiments.

When the optimum results of the parameters affecting thermal conductivity and flexural stress were evaluated in terms of volumetric ratio, thermal conductivity was found to be $15 \%$ and flexural stress $5 \%$. 
Therefore, a maximum volume of SiC powder filler should be added to increase thermal conductivity, while a minimum volume of $\mathrm{SiC}$ powder filler should be added in order not to reduce bending strength. Increasing the filler ratio has been reported to increase thermal conductivity in direct proportion but decrease the bend strength in inverse proportion $[7,10,14]$. In the present study, the mixing style had no effect on thermal conductivity. The optimum particle size was $125 \mu \mathrm{m}$ for both thermal conductivity and maximum stress. The most effective parameter for thermal conductivity in terms of the percentage of contribution was the volume ratio, while the particle size was the most effective parameter for maximum stress.

The SEM images (Figure 5 A-C) revealed that the nanoscale filler was not structurally compatible with PMMA and was not integrated well. The flexural strength and thermal conductivity results were the lowest for the nanofiller groups. The SEM images of groups containing $125-\mu \mathrm{m}$ particle size filler (Fig. 5 G-I) demonstrate that this size filler was structurally compatible with PMMA and was integrated well. This explains the high flexural strength and thermal conductivity values. The SEM images also show that the mixing type did not affect the dispersion of filler powders, confirming the experimental results. The most important criterion in the distribution is that the particle sizes of PMMA $(121 \mu \mathrm{m})$ and $\mathrm{SiC}(125 \mu \mathrm{m})$ powders were similar.

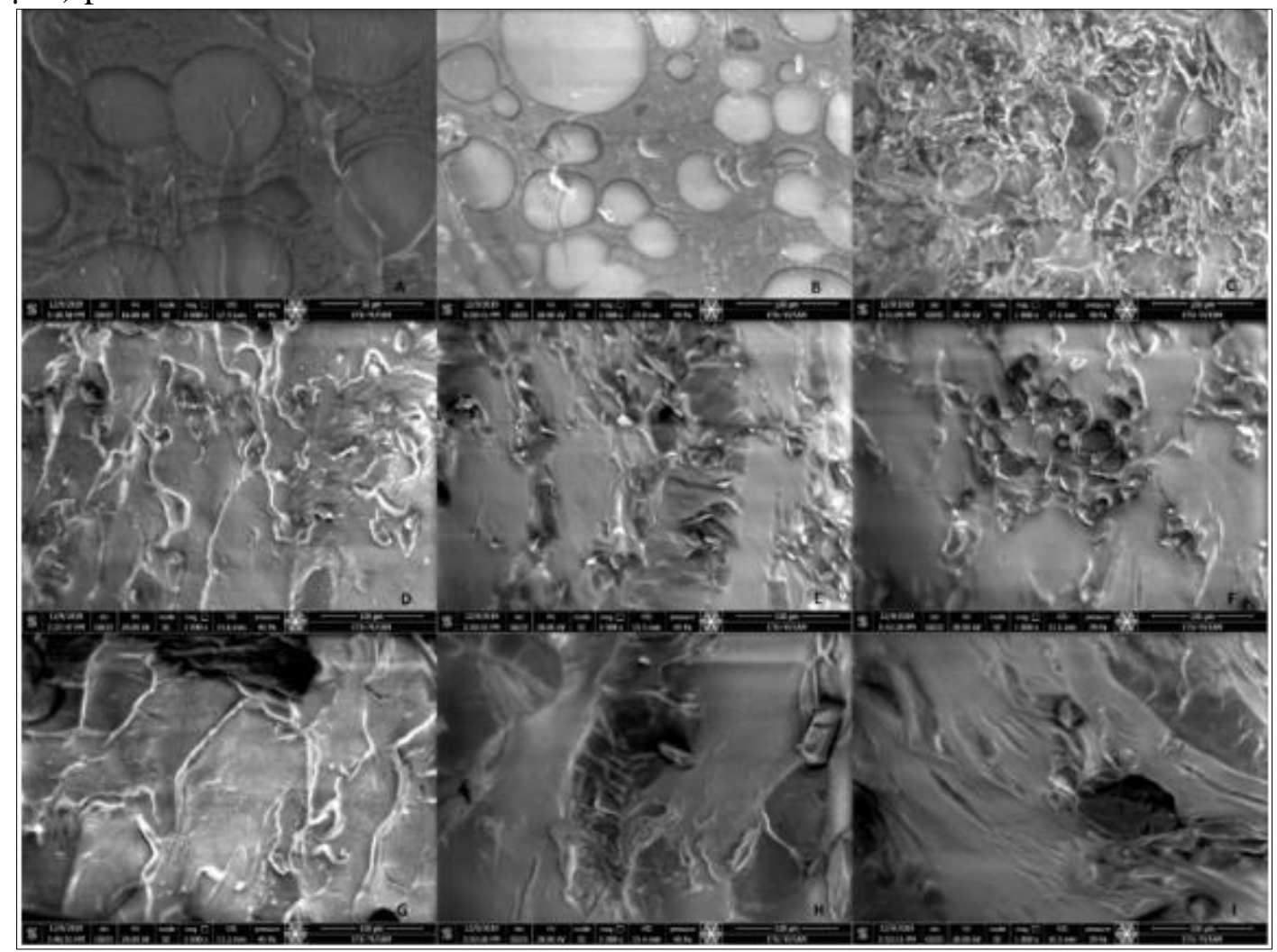

Figure 5. Scanning electron microscope images (original magnification $\times 1000$ ).

A, Experiment $1(0.2 \mu \mathrm{m}$ and $5 \% \mathrm{SiC}$ powder, $0.5 \%$ silane, manuel mixing). B, Experiment 2

$(0.2 \mu \mathrm{m}$ and $10 \% \mathrm{SiC}$ powder, $1 \%$ silane, stir mixing). C, Experiment $3(0.2 \mu \mathrm{m}$ and

$15 \% \mathrm{SiC}$ powder, $1.5 \%$ silane, mechanical alloying). D, Experiment 4 (37 $\mu \mathrm{m}$ and $5 \% \mathrm{SiC}$ powder,

$1 \%$ silane, mechanical alloying). E, Experiment 5 (37 $\mu \mathrm{m}$ and $10 \% \mathrm{SiC}$ powder, $1.5 \%$ silane, manuel mixing). F, Experiment $6(37 \mu \mathrm{m}$ and $15 \% \mathrm{SiC}$ powder, $0.5 \%$ silane, stir mixing).

G, Experiment 7 (125 $\mu \mathrm{m}$ and $5 \% \mathrm{SiC}$ powder, $1.5 \%$ silan, stir mixing). H, Experiment $8(125 \mu \mathrm{m}$ and $10 \% \mathrm{SiC}$ powder, $0.5 \%$ silane, mechanical alloying). I, Experiment 9 (125 $\mu \mathrm{m}$ and $15 \% \mathrm{SiC}$ powder, $1 \%$ silane, manuel mixing).

The authors are unaware of an optimization study on the homogeneous distribution of filler powders in PMMA. In the current study, mixing type has a significant effect on flexural strength values only. In 
the stirring process in a smaller mill, the balls may contact the powders more and cause more homogeneous dispersion. However, additional studies are indicated.

Covering the palate with a denture base has been reported to reduce taste [5,6] and adding $20 \%$ aluminum particles improved temperature sensation and led to better patient satisfaction [23]. Similarly, in our previous study [10], when the $\mathrm{SiC}$ filler powder with $37 \mu \mathrm{m}$ particle size was added to the denture base material, its flexural strength and thermal conductivity were improved. However, especially in experimental groups containing nanosized powders and smaller particle sizes (nanoSiC and nano HA), the flexural strength was reduced. In the present study, the parameters were limited so as not to decrease the maximum stress below $65 \mathrm{MPa}$ while increasing the thermal conductivity. Both thermal conductivity and bend strength values of PMMA containing microsized SiC powder were significantly higher than those of the group containing nanosized $\mathrm{SiC}$ powder [10]. $\mathrm{SiC}$ is a biocompatible material [13,15-17] and increases the thermal conductivity of denture resin without altering flexural properties [17].

Silane containing 3-methacryloxypropyltrimethoxysilane (MTS) has been reported to increase the bond of resin cements to ceramic [37]. In the present study, the amount of silane has no effect on thermal conductivity but slightly affected flexural strength. Silane coupling has a negligible effect in terms of both thermal conductivity and flexural strength. Limitations of this study include the limited number of different particle size filler powders and the limited number of different mixing techniques. Filling powders with different particle sizes can be used in future studies and more advanced mixing techniques can be evaluated.

In future research, different optimization tools and algorithms can be used and compared, for example, response surface methodology and colonial bee algorithm. In addition, materials such as alumina which improve heat transfer properties can be evaluated in terms of both thermal conductivity and flexural strength.

\section{Conclusions}

Based on the findings of this in vitro study, the following conclusions were drawn:

1. Optimized results for thermal diffusivity were a particle size of $125 \mu \mathrm{m}$, a volumetric rate of $15 \%$, a silane coupling rate of $1 \%$, and a mixing style of stir.

2. The most effective parameter affecting thermal diffusivity was the volumetric rate of SiC.

3. Optimized results for flexural strength were a particle size of $125 \mu \mathrm{m}$, a volumetric rate of $5 \%$, a silane coupling rate of $1 \%$, and a mixing style of stir.

4. The most effective parameter affecting the flexural strength was the particle size of SiC.

5. The Taguchi method can be reliably used to reinforce PMMA with SiC, reducing experimental costs and time.

\section{References}

1.AYDIN A, TERZIOĞLU H, AKINAY A, ULUBAYRAM K, HASIRCI N. Bond strength and failure analysis of lining materials to denture resin. Dent Mater 1999; 15:211-8.

2.GREEN BG, FRANKMANN SP. The effect of cooling on the perception of carbohydrate and intensive sweeteners. Physiol. Behav 1988; 43:515-9.

3.NAKAMURA M, KURIHARA K. Temperature dependence of amiloride-sensitive and-insensitive components of rat taste nerve response to NaCl. Brain Res 1988; 444:159-64.

4. NAKAMURA M, KURIHARA K. Differential temperature dependence of taste nerve responses to various taste stimuli in dogs and rats. Am J Physiol-Reg I 1991;261: R1402-R8.

5. FURUYA-YOSHINAKA M, YOSHINAKA M, ISOGAI F, MAEDA Y. Influence of an experimental palatal plate on thermal perception. J Prosthodont Res 2009;53: 193-6.

6. HIRANO K, HIRANO S, HAYAKAWA I. The role of oral sensorimotor function in masticatory ability. J Oral Rehabil 2004; 31:199-205.

7. SEHAJPAL S, SOOD V. Effect of metal fillers on some physical properties of acrylic resin. J Prosthet Dent 1989; 61:746-51. 
8. KAPUR KK, FISCHER EE. Effect of denture base thermal conductivity on gustatory response. J Prosthet Dent 1981;46:603-9.

9. ANUSAVICE K.J, PHILLIPS. R.W. Phillips' science of dental materials. 12th ed. St. Louis: Mosby/Elsevier; 2012. p. 351

10. KUL E, ALADAĞ LI, YESILDAL R. Evaluation of thermal conductivity and flexural strength properties of poly (methyl methacrylate) denture base material reinforced with different fillers. J Prosthet Dent 2016; 116:803-10.

11. ATLA J, MANNE P, GOPINADH A, SAMPATH A, MUVVA SB, KISHORE K, et al. The effect of Al2O3 addition on the thermal diffusivity of heat activated acrylic resin. J Clin Diagn Res 2013; 7:1797.

12. MESSERSMITH PB, OBREZ A, LINDBERG S. New acrylic resin composite with improved thermal diffusivity. J Prosthet Dent 1998; 79:278-84.

13. CAPPI B, NEUSS S, SALBER J, TELLE R, KNÜCHEL R, FISCHER H. Cytocompatibility of high strength non-oxide ceramics. J Biomed Mater Res A 2010;93:67-76.

14. KAMIL AS, AL-JUDY HJ. Effect of addition of silanized silicon carbide nanoparticles on some physical properties of heat cured acrylic denture base material. J Res Med Den Sci 2018; 6:86-95.

15. MAZZOCCHI M, BELLOSI A. On the possibility of silicon nitride as a ceramic for structural orthopaedic implants. Part I: processing, microstructure, mechanical properties, cytotoxicity. J Mater Sci Mater Med 2008; 19:2881-7.

16. HOWLETT C, MCCARTNEY E, CHING W. The effect of silicon nitride ceramic on rabbit skeletal cells and tissue. An in vitro and in vivo investigation. Clin Orthop Relat R 1989:293-304.

17. DION I, BORDENAVE L, LEFEBVRE F, BAREILLE R, BAQUEY C, MONTIES J-R, et al. Physico-chemistry and cytotoxicity of ceramics. J Mater Sci Mater Med 1994; 5:18-24.

18. CENGEL Y, GHAJAR A. Transient heat conduction. Heat and mass transfer: fundamentals and applications; New York: McGraw-Hill Education; 2014. p. 267

19. McCABE J, WILSON H. The use of differential scanning calorimetry for the evaluation of dental materials: Part II. Denture base materials. J. Oral Rehabil 1980; 7:235-43.

20. LIDE DR. CRC handbook of chemistry and physics: a ready-reference book of chemical and physical data. 76th ed. Boca Raton: CRC press; 1995. p. 345

21. VENKANNA B. Fundamentals of heat and mass transfer. India: PHI Learning Pvt. Ltd.; 2010. p. 508.

22. ELLAKWA AE, MORSY MA, EL-SHEIKH AM. Effect of aluminum oxide addition on the flexural strength and thermal diffusivity of heat-polymerized acrylic resin. J Prosthodont 2008; 17:439-44.

23.YADAV P, MITTAL R, SOOD VK, GARG R. Effect of incorporation of silane-treated silver and aluminum microparticles on strength and thermal conductivity of PMMA. J Prosthodont 2012; 21:54651.

24. KACKAR RN. Off-line quality control, parameter design, and the Taguchi method. J Qual Technol $1985 ; 17: 176-88$.

25.NAIR VN, ABRAHAM B, MACKAY J, BOX G, KACKER RN, LORENZEN TJ, et al. Taguchi's parameter design: a panel discussion. Technometrics 1992; 34:127-61.

26.BYRNE DM, TAGUCHI S. The Taguchi approach to parameter design. Qual Prog 1987; 20:19-26. 27.ROY RK, Design of experiments using the Taguchi approach: 16 steps to product and process improvement. New York: John Wiley \& Sons; 2001. p. 560.

28.CHAIJAREENONT P, TAKAHASHI H, NISHIYAMA N, ARKSORNNUKIT M. Effect of different amounts of 3-methacryloxypropyltrimethoxysilane on the flexural properties and wear resistance of alumina reinforced PMMA. Dent Mater J 2012; 31:623-8.

29.LIAO Y-S, LIN T-C, LEE M-S, SU P-Y, CHEN Y-L, CHANG H-H, et al. Optimal parameters of dental ultrasonic instrument diamond coating for enamel removal. J Dent Sci 2015; 10:128-32.

30.YESILDAL F, YAKUT K. Optimization of the spray cooling parameters for a heat sink by the Taguchi method. Atomization Spray 2017; 27:1063-75. 
31.CHENG C-J, LIN C-L, SHAN Y-F. Multifactorial analysis of variables influencing the fracture strength of repair joints for provisional restorative materials using the statistically based Taguchi method. J Dent Sci 2010; 5:90-9.

32. YAKUT K, ALEMDAROGLU N, SAHIN B, CELIK C. Optimum design-parameters of a heat exchanger having hexagonal fins. Appl Energ 2006; 83:82-98.

33. SAHIN B, YAKUT K, KOTCIOGLU I, CELIK C. Optimum design parameters of a heat exchanger. Appl Energ 2005; 82:90-106.

34.*** International Organization for Standardization. ISO 9693-1. Dentistry compatibility testing. Part 1: Metal-ceramic systems. Geneva: International Organization for Standardization; 2012. ISO Store Order: OP-184149 (Date: 2017-06-09). Available at: http://www.iso.org/iso/home.html.

35. VOJDANI M, BAGHERI R, KHALEDI AAR. Effects of aluminum oxide addition on the flexural strength, surface hardness, and roughness of heat-polymerized acrylic resin. J Dent Sci 2012; 7:238-44. 36.***American Society of the International Association for Testing and Materials. International designation: E1530e66. Standard test method for evaluating the resistance to thermal transmission of materials by guarded heat flow meter technique. West Conshohocken: ASTM; 2006.

37. TAIRA Y, SAKAI M, SAWASE T. Effects of primer containing silane and thiophosphate monomers on bonding resin to a leucite-reinforced ceramic. J Dent 2012; 40:353-8.

38. PHADKE MS, KACKAR RN, SPEENEY DV, GRIECO MJ. Off-line quality control in integrated circuit fabrication using experimental design. Bell Syst Tech J 1983; 62:1273-309.

39.HAMMERSCHMIDT U, MEIER V. New transient hot-bridge sensor to measure thermal conductivity, thermal diffusivity, and volumetric specific heat. Int J Thermophys 2006; 27:840-65.

Manuscript received: 22.07 .2020 